\title{
Saussureae Radix Attenuates Neuroinflammation in LPS- Stimulated Mouse BV2 Microglia via HO-1/Nrf-2 Induction and Inflammatory Pathway Inhibition
}

\author{
You-Chang Oh $\mathbb{D}$, Wei Li, and Jang-Gi Choi \\ Korean Medicine (KM)-Application Center, Korea Institute of Oriental Medicine, 70, Cheomdanro, Dong-gu, \\ Daegu 41062, Republic of Korea \\ Correspondence should be addressed to You-Chang Oh; ulivuli@kiom.re.kr
}

Received 10 November 2020; Revised 4 March 2021; Accepted 11 March 2021; Published 19 March 2021

Academic Editor: Ghulam Ashraf

Copyright (C) 2021 You-Chang Oh et al. This is an open access article distributed under the Creative Commons Attribution License, which permits unrestricted use, distribution, and reproduction in any medium, provided the original work is properly cited.

\begin{abstract}
The activation of microglial cells and their subsequent neuroinflammatory reactions are related to various degenerative brain diseases. Therefore, the regulation of microglial cell activation is an important point for the research of therapeutic agents for treating or preventing neurodegenerative disorders. Saussureae Radix (SR) is the root of Saussurea lappa Clarke, and it has been used for a long time as an herbal medicine in East Asia to treat indigestion and inflammation of the digestive system. In previous studies, however, the effect of SR ethanolic extract on microglial cell-mediated neuroinflammation was not fully explained. In this study, we explored the antineuroinflammatory activities and molecular mechanisms of SR in microglial cells stimulated with LPS (lipopolysaccharide). Our results illustrated that SR does not cause cytotoxicity and significantly weakens the production of nitric oxide (NO) and inflammatory cytokines. SR treatment also inhibited the expression of inducible nitric oxide synthase (iNOS) and cyclooxygenase- (COX-) 2, induced heme oxygenase- (HO-) 1, and activated the nuclear factor erythroid 2-related factor 2 (Nrf-2) pathway. In addition, SR significantly repressed the transcriptional activities of the nuclear factor- (NF-) $\kappa \mathrm{B}$ and activator protein- (AP-) 1. Furthermore, SR effectively inhibited the phosphorylation of mitogen-activated protein kinase (MAPK) and Janus kinase (JAK)/signal transducer and activator of transcription (STAT). Isolation and highperformance liquid chromatography (HPLC) analysis indicated two major sesquiterpenoids (costunolide and dehydrocostuslactone). These compounds significantly inhibited the production of neuroinflammatory mediators and induced HO-1 expression. These findings show that SR could be a potential candidate for the treatment of inflammation-related degenerative brain diseases.
\end{abstract}

\section{Introduction}

Microglia are important immune cells, and they play critical roles in the central nervous system (CNS) in the brain. In normal conditions, they are continually scavenging the CNS for abnormal brain cells and pathogens, and they also help regulate synaptic homeostasis [1]. However, activated conditions of microglia give rise to neurotoxic substance production, such as inflammatory mediators and proteins, all of which are implicated in neurodegenerative disorders [2]. LPS acts as a prototypical endotoxin, inducing inflammation, sepsis, and death. LPS is thus commonly used to create in vitro models of inflammation [3]. In activated conditions upon
LPS stimulation, MAPKs in turn mediate some signal pathways, such as the transcription factors NF- $\kappa$ B and AP-1 [4]. $\mathrm{AP}-1$ and NF- $\kappa \mathrm{B}$ are closely connected in the production of inflammatory molecules, including iNOS and cytokines [5]. In addition, the JAK/STAT is another important pathway with critical roles in immune responses via the release of growth factors and proinflammatory cytokines [6]. Accordingly, regulation of the MAPK, NF- $\kappa \mathrm{B}, \mathrm{AP}-1$, and JAK/STAT pathways can be important for treating inflammatory diseases.

HO-1 is an enzyme that promotes the decomposition of heme into carbon monoxide (CO) and biliverdin. $\mathrm{HO}-1$ is highly inducible, and it is expressed in many neuronal cells, 
including HT22 and BV2 cells [7]. In addition, HO-1 inhibits the production of proinflammatory factors, such as $\mathrm{NO}$ and inflammatory cytokines [8]. HO-1 and its by-product $\mathrm{CO}$ decrease iNOS expression, thereby reducing the level of iNOS-derived NO [9]. HO-1 production is induced by activation of redox-dependent transcription factor Nrf-2 [10]. In the inflammatory process, free Nrf-2 translocates to the nucleus and consequently induces $\mathrm{HO}-1$ production [11]. Thus, some recent studies identified the importance of HO1 for immunomodulation or anti-inflammatory efficacy.

SR has long been used as a medicinal herb to treat various diseases of the digestive system. Previous studies reported that SR can ameliorate ethephon-induced reproductive toxicity in rats and alleviate house dust mite-induced atopic-like dermatitis in $\mathrm{Nc} / \mathrm{Nga}$ mice $[12,13]$. Also, another review study showed that SR exhibits anticancer, anti-inflammatory, antiulcer, and cholagogic effects [14]. However, the influence of SR and its molecular mechanisms on neuroinflammation in microglial cells remain unknown. Thus, the present study investigated the inhibitory effect of SR on neuroinflammation and its mechanisms using BV2 microglial cells upon LPS stimulation. To evaluate the antineuroinflammatory efficacy of major constituents in SR, we isolated two major sesquiterpenoids, costunolide (1) and dehydrocostuslactone (2). Furthermore, two isolated compounds were also investigated quantitatively using HPLC analysis, and we explored its antineuroinflammatory efficacy.

\section{Materials and Methods}

2.1. Materials and Reagents. Dulbecco's modified Eagle's medium (DMEM), fetal bovine serum (FBS), and antibiotics were obtained from Hyclone (Logan, UT, USA). LPS, dexamethasone, bovine serum albumin (BSA), and dimethyl sulfoxide (DMSO) were purchased from Sigma-Aldrich (St. Louis, MO, USA). $100 \mathrm{~mm}$ culture dishes and 6-96-well plates were obtained from Sarstedt (Nümbrecht, Germany). A cell-counting kit (CCK) was purchased from Dojindo (Kumamoto, Japan). Enzyme-linked immunosorbent assay (ELISA) antibody sets were obtained from eBioscience (San Diego, CA, USA). Various primary antibodies and horseradish peroxidase- (HRP-) conjugated secondary antibodies were purchased from Cell Signaling Technology, Inc. (Boston, MA, USA) and Novus Biologicals (Centennial, CO, USA). The Alexa Fluor 488-conjugated anti-rabbit secondary antibody was obtained from Invitrogen (Carlsbad, CA, USA). An RNA extraction kit was obtained from iNtRON Biotech (Daejeon, Korea). Oligonucleotide primers for real-time reverse transcription-polymerase chain reaction (RT-qPCR), DNA synthesizing kits, and AccuPower ${ }^{\circledR} 2 \mathrm{x}$ GreenStar qPCR Master Mix were obtained from Bioneer (Daejeon, Korea). SR ethanolic extract (used 100\% ethanol) was obtained from the Korea Plant Extract Bank (Ochang, Korea).

2.2. Cell Culture, Test Drug Treatment, and Stimulation. BV2 cells were grown in DMEM (contains 1\% antibiotics and 10\% FBS) and incubated in a humidified $5 \% \mathrm{CO}_{2}$ atmosphere at $37^{\circ} \mathrm{C}$. To stimulate the microglia, LPS $(100 \mathrm{ng} / \mathrm{mL})$ was used in the presence or absence of SR $(1,10,50$, or $100 \mu \mathrm{g} / \mathrm{mL})$, costunolide $(1,10$, or $25 \mu \mathrm{M})$, dehydrocostuslactone (1, 5, or $10 \mu \mathrm{M})$, or DMSO $(0.1 \%$, vehicle control (VC)).

2.3. Cell Viability Test. The potential cytotoxicity of SR was examined by CCK assay. BV2 cells were seeded and preincubated for $18 \mathrm{~h}$, and various concentrations of SR, DMSO, or LPS were added to the cells. After incubation for $24 \mathrm{~h}$, the CCK solution was added and incubated for an additional $1 \mathrm{~h}$. Cell viability was calculated from the optical density at $450 \mathrm{~nm}$ using an ELISA reader.

2.4. Analysis of NO Secretion. NO levels were examined by measuring nitrite concentrations in the culture medium. BV2 cells were plated, preincubated with SR, costunolide, dehydrocostuslactone, or DMSO for $1 \mathrm{~h}$, and stimulated with LPS for $24 \mathrm{~h}$. Then, $100 \mu \mathrm{L}$ of the Griess reagent was added to each well. After incubation at room temperature for $5 \mathrm{~min}$, absorbance was measured at $570 \mathrm{~nm}$ using an ELISA reader.

2.5. Cytokine Determination. For ELISA, BV2 cells were seeded and incubated for $18 \mathrm{~h}$. The cells were pretreated with several concentrations of SR, costunolide, dehydrocostuslactone, or DMSO for $1 \mathrm{~h}$, then stimulated with LPS for an additional $6 \mathrm{~h}$. The inflammatory cytokine levels of the culture medium were measured by the ELISA antibody set in accordance with the manufacturer's protocol.

2.6. Total RNA Extraction and RT-qPCR. Total RNA extraction and cDNA synthesis were carried out using easy-BLUE ${ }^{\mathrm{TM}}$ RNA extraction kits (iNtRON Biotech) and AccuPower ${ }^{\circledR}$ CycleScript RT PreMix (Bioneer), respectively, and the methods of previous studies were referred [15]. The experimental setting, specific methods, and PCR conditions for RT-qPCR referred to our previous research methods [15]. The sequence of oligonucleotide primers used in this study is shown in Table 1 [15]. The amplification and analysis were performed using a QuantStudio 6 Flex Real-time PCR System (Thermo Fisher Scientific, Rockford, IL, USA), and each sample was compared by the relative CT method. The results of RT-qPCR were presented as gene induction fold, which was calculated using the internal control.

2.7. Preparation of Whole-Cell, Cytosolic, and Nuclear Extracts. To obtain whole-cell lysates, pellets were resuspended in the radioimmunoprecipitation assay lysis buffer (Millipore, Bedford, MA, USA) containing protease and phosphatase inhibitors. Cytosolic and nuclear fractions were isolated using NE-PER ${ }^{\mathrm{TM}}$ nuclear and cytoplasmic extraction reagents (Thermo Fisher Scientific) as described by the manufacturer.

2.8. Western Blotting Analyses. Total proteins were normalized using Bradford's method [16]. The proteins were separated using sodium dodecyl sulfate-polyacrylamide gel electrophoresis and transferred to a polyvinylidene fluoride membrane (Millipore, Bedford, MA, USA). After blocking nonspecific binding sites using 3\% BSA, membranes were incubated with each primary antibody at $4^{\circ} \mathrm{C}$ overnight. The membranes were subsequently incubated with each HRP-conjugated secondary antibody. Protein levels were 
TAble 1: Primers used for RT-qPCR.

\begin{tabular}{|c|c|}
\hline Target gene & Primer sequence \\
\hline \multirow{2}{*}{ TNF- $\alpha$} & F: 5' -TTCTGTCTACTGAACTTCGGGGTGATCGGTCC-3' \\
\hline & R: $5^{\prime}$-GTATGAGATAGCAAATCGGCTGACGGTGTGGG-3' \\
\hline \multirow{2}{*}{ IL-6 } & F: $5^{\prime}$-TCCAGTTGCCTTCTTGGGAC-3' \\
\hline & R: 5'-GTGTAATTAAGCCTCCGACTTG-3' \\
\hline \multirow[b]{2}{*}{ IL- $1 \beta$} & F: 5' -ATGGCAACTGTTCCTGAACTCAACT-3' \\
\hline & R: 5'-CAGGACAGGTATAGATTCTTTCCTTT-3' \\
\hline \multirow{2}{*}{ iNOS } & F: 5'-GGCAGCCTGTGAGACCTTTG-3' \\
\hline & R: 5'-GCATTGGAAGTGAAGCGTTTC-3' \\
\hline \multirow{2}{*}{ COX-2 } & F: $5^{\prime}$-TGAGTACCGCAAACGCTTCTC- $3^{\prime}$ \\
\hline & R: 5'-TGGACGAGGTTTTTCCACCAG-3' \\
\hline \multirow{2}{*}{$\mathrm{HO}-1$} & F: $5^{\prime}$-TGAAGGAGGCCACCAAGGAGG-3' \\
\hline & R: 5' -AGAGGTCACCCAGGTAGCGGG-3' \\
\hline \multirow{2}{*}{$\beta$-Actin } & F: 5' -AGAGGGAAATCGTGCGTGAC-3' \\
\hline & R: $5^{\prime}$-CAATAGTGATGACCTGGCCGT-3' \\
\hline
\end{tabular}

F: forward; R: reverse.

quantified using a ChemiDoc ${ }^{\mathrm{TM}}$ Touch Imaging System (BioRad). The information about the various primary and secondary antibodies is listed in Table 2.

2.9. Immunofluorescence Staining. BV2 cells were seeded and incubated overnight. After treatment with SR and LPS, BV2 cells were incubated for 1 (NF- $\kappa \mathrm{B}$ p65) or $3 \mathrm{~h}$ (Nrf-2). Cells were washed three times with phosphate-buffered saline (PBS) and fixed in $4 \%$ paraformaldehyde for $30 \mathrm{~min}$ at room temperature. After blocking, immobilized cells were incubated with each primary antibody overnight at $4^{\circ} \mathrm{C}$, washed three times with PBS, and incubated with the Alexa Fluor 488-conjugated secondary antibody. Cells were incubated with 4,6-diamidino-2-phenylindole (DAPI) for $10 \mathrm{~min}$ at room temperature and observed under a fluorescence microscope [17].

2.10. Plant Material. Dried SR was kindly provided from Bomyeong Herbal Market, Seoul, in 2016. Its scientific name was identified by one of the authors (Dr. Wei Li). A voucher specimen (ID-160078) was deposited at the Herbarium of Korean Medicine (KM)-Application Center, Korea Institute of Oriental Medicine, Republic of Korea.

2.11. Extraction and Isolation. The dried SR (500.0 g) was reflux extracted three times using EtOH $(1.5 \mathrm{~L})$. The total extraction $(80.0 \mathrm{~g})$ of $\mathrm{EtOH}$ was suspended in deionized water and partitioned with EtOAc and water fraction, yielding EtOAc (1A, 38.0 g) and water (1B, $41.5 \mathrm{~g})$. The EtOAc fraction was subjected to silica gel column chromatography with a gradient of hexane-EtOAc-MeOH $(10: 1: 0,9: 1: 0$, $8: 1: 0,6: 1: 0.1,5: 1: 0.1,4: 1: 0.1,3: 1: 0.1$, and $2: 1: 0.1$, with $1.0 \mathrm{~L}$ for each step) to give 11 fractions (Fr. 1A-1-1A11). Fraction 1A-2 was isolated with a gradient of $\mathrm{H}_{2} \mathrm{O}-\mathrm{MeOH}$
$(1: 4,1: 3,1: 2$, and $1: 1$ and $\mathrm{MeOH})$ by MPLC using the YMC C18 column to give 8 fractions (Fr. 1C-1-1C-8). The fraction 1C-2 was separated by a Sephadex LH-20 column and eluted by $\mathrm{MeOH}$, and its subfraction was isolated by prep-HPLC to give compound 1 ( $460.0 \mathrm{mg}$; purity $>97 \%$ ) and compound 2 (586.0 mg; purity > 95\%).

2.12. Sample Preparation for HPLC Analysis. The standard stock solutions for HPLC were prepared by dissolving accurately weighed compounds in $100 \%$ methanol $(1 \mathrm{mg} / \mathrm{mL})$. SR extract was prepared at a concentration of $10 \mathrm{mg} / \mathrm{mL}$. All solutions for analysis were filtered through $0.45 \mu \mathrm{m} \mathrm{RC}$ membrane syringe filters (Sartorius, Germany).

2.13. Optimization of Chromatographic Conditions. HPLC analysis was performed using a Dionex UltiMate 3000 system (Dionex Corp., Sunnyvale, CA, USA) equipped with a binary pump, autosampler, column oven, and diode array UV/VIS detector (DAD). System control and data analysis were carried out using Dionex Chromeleon software. Separation was carried out on a Luna C18 column $(250 \times 4.6 \mathrm{~mm}$, $5 \mu \mathrm{m}$, Phenomenex, Torrance, CA, USA), with the column oven temperature kept at $30^{\circ} \mathrm{C}$, at a UV wavelength of $200 \mathrm{~nm}$. The mobile phase consisted of water (solvent A) and methanol (solvent B) with $25: 75$ at $0-20 \mathrm{~min}, 75 \%-$ $100 \%$ of $\mathrm{B}$ at $20-30 \mathrm{~min}$ in a flow rate of $1.0 \mathrm{~mL} / \mathrm{min}$.

2.14. Validation of the Method. The linear calibration curves were plotted with diluted five different concentrations. Linearity was assessed by computing the correlation coefficient $\left(R^{2}\right)$ of the calibration curve for two compounds. Five concentrations of compounds were analyzed in triplicate. Regression equations were calculated using the equation $y$ 
TABLE 2: Primary and secondary antibodies used for Western blotting analysis.

\begin{tabular}{|c|c|c|c|c|}
\hline Antibody & Corporation & Product no. & RRID & Dilution rate \\
\hline iNOS & Cell Signaling & \#13120 & AB_2687529 & $1: 1000$ \\
\hline $\mathrm{COX}-2$ & Cell Signaling & \#4842 & AB_2085144 & $1: 1000$ \\
\hline$\beta$-Actin & Santa Cruz & \#SC-47778 & AB_626632 & $1: 1000$ \\
\hline $\mathrm{HO}-1$ & Cell Signaling & \#82206 & AB_2799989 & $1: 1000$ \\
\hline Nrf-2 & Novus Biologicals & \#NBP1-32822 & AB_10003994 & $1: 1000$ \\
\hline TBP & Cell Signaling & \#8515 & AB_10949159 & $1: 1000$ \\
\hline NF- $\kappa$ B p65 & Cell Signaling & $\# 8242$ & AB_10859369 & $1: 1000$ \\
\hline $\mathrm{P}-\mathrm{I} \kappa \mathrm{B} \alpha$ & Cell Signaling & $\# 2859$ & AB_561111 & $1: 1000$ \\
\hline $\mathrm{I} \kappa \mathrm{B} \alpha$ & Cell Signaling & $\# 4814$ & AB_390781 & $1: 1000$ \\
\hline P-ERK & Cell Signaling & $\# 4377$ & AB_331775 & $1: 1000$ \\
\hline ERK & Cell Signaling & \#9102 & AB_330744 & $1: 1000$ \\
\hline P-p38 & Cell Signaling & \#9211 & AB_331641 & $1: 1000$ \\
\hline p38 & Cell Signaling & \#9212 & AB_330713 & $1: 1000$ \\
\hline P-JNK & Cell Signaling & \#9251 & AB_331659 & $1: 1000$ \\
\hline JNK & Cell Signaling & \#9252 & AB_2250373 & $1: 1000$ \\
\hline P-c-Jun & Cell Signaling & $\# 3270$ & AB_2129575 & $1: 1000$ \\
\hline c-Jun & Cell Signaling & \#9165 & AB_2130165 & $1: 1000$ \\
\hline c-Fos & Cell Signaling & $\# 2250$ & AB_2247211 & $1: 1000$ \\
\hline P-JAK2 & Cell Signaling & 3771 & AB_330403 & $1: 1000$ \\
\hline JAK2 & Cell Signaling & 3230 & AB_2128522 & $1: 1000$ \\
\hline P-STAT1 & Cell Signaling & 9167 & AB_561284 & $1: 1000$ \\
\hline STAT1 & Cell Signaling & 14994 & AB_2737027 & $1: 1000$ \\
\hline P-STAT3 & Cell Signaling & 9145 & AB_2491009 & $1: 1000$ \\
\hline STAT3 & Cell Signaling & 12640 & AB_2629499 & $1: 1000$ \\
\hline 2nd anti-mouse & Cell Signaling & $\# 7076$ & AB_330924 & $1: 5000$ \\
\hline 2nd anti-rabbit & Cell Signaling & \#7074 & AB_2099233 & $1: 5000$ \\
\hline
\end{tabular}

$=a x \pm b$, where $x$ and $y$ are the concentration and peak area of the compound, respectively.

2.15. Statistical Analyses. All data are presented as the mean \pm standard error of the mean of three independent experiments. Statistical significance was analyzed using one-way analysis of variance followed by Dunnett's test after comparing the LPS and each treated sample. Statistical significance was defined as $p<0.05$.

\section{Results}

3.1. Influence of SR on the Viability of BV2 Cells. To examine the potential cytotoxic effects of SR on BV2 cells, CCK assays were conducted. As presented in Figure 1(a), treatment with SR $(1-100 \mu \mathrm{g} / \mathrm{mL})$ for $24 \mathrm{~h}$ caused no cytotoxicity, and slight proliferation was observed at concentrations of $\geq 50 \mu \mathrm{g} / \mathrm{mL}$. Also, $0.1 \%$ DMSO used as a vehicle control had no significant effect on cell viability.

3.2. Effects of SR on the Secretion of NO and Cytokines. To investigate the antineuroinflammatory efficacy of SR, we first evaluated the NO production following LPS stimulation using Griess assay. As presented in Figure 1(b), LPS treatment strongly elevated NO levels, whereas pretreatment with
SR strongly diminished NO production in a concentrationdependent manner. We next investigated the influences of SR on the LPS-induced inflammatory cytokine production and expression of their mRNAs using ELISA and RT-qPCR, respectively. As shown in Figures 1(c)-1(g), LPS-treated cells strongly increased the production of tumor necrosis factor(TNF-) $\alpha$ and interleukin- (IL-) 6 as well as their mRNA levels, whereas SR treatment suppressed cytokine and mRNA levels in a concentration-dependent manner. In addition, treatment of $0.1 \%$ DMSO (vehicle control) did not affect the production of neuroinflammatory mediators.

3.3. Effects of SR on the Expression of iNOS and COX-2. We next researched the protein and mRNA expression of iNOS and COX-2, the synthesizing enzymes of NO and prostaglandin $E_{2}$, respectively. The results indicated that pretreatment with SR effectively suppressed LPS-induced iNOS and COX-2 expression at the protein and mRNA levels (Figures 2(a) and 2(b)).

3.4. Effects of $S R$ on the Induction of HO-1 and Nuclear Translocation of Nrf-2. HO-1 was effectively induced by SR pretreatment even under LPS stimulation. HO-1 protein expression was strongly induced by $\geq 50 \mu \mathrm{g} / \mathrm{mL}$ SR, and its mRNA expression was induced by $100 \mu \mathrm{g} / \mathrm{mL}$ SR 
Cell viability

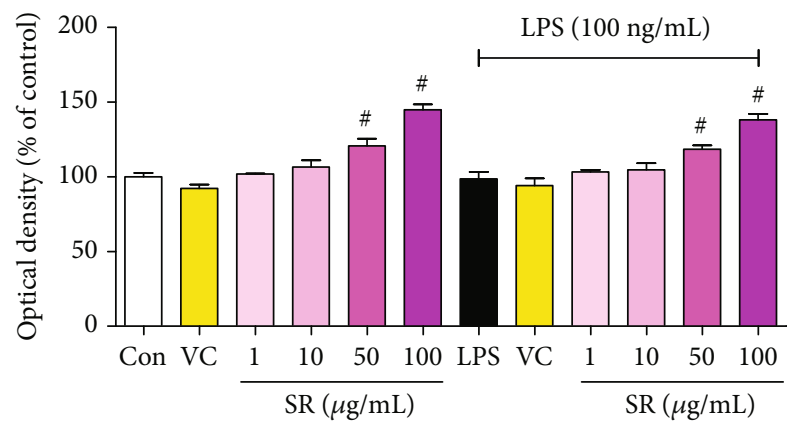

(a)

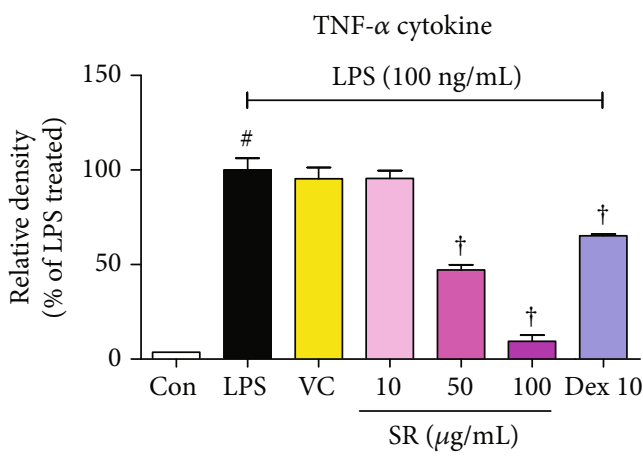

(c)

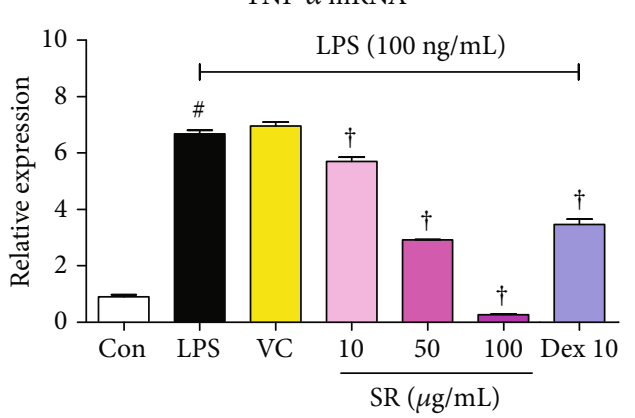

(e)

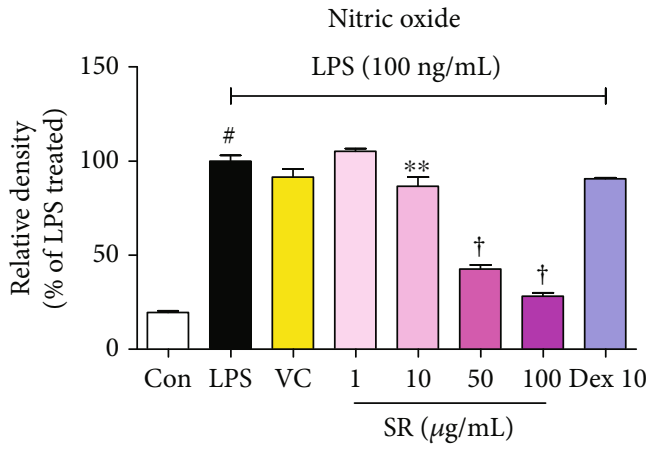

(b)

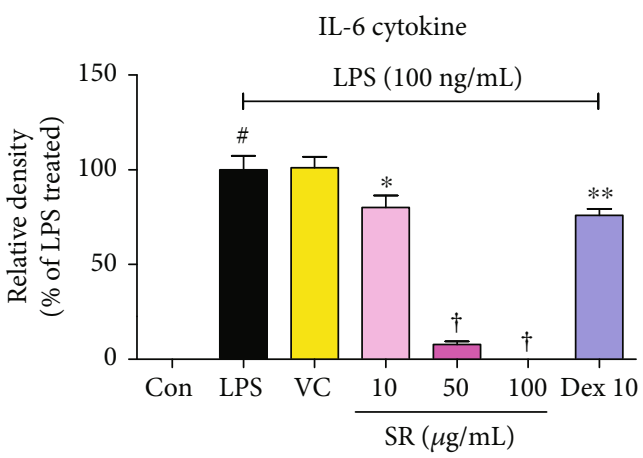

(d)

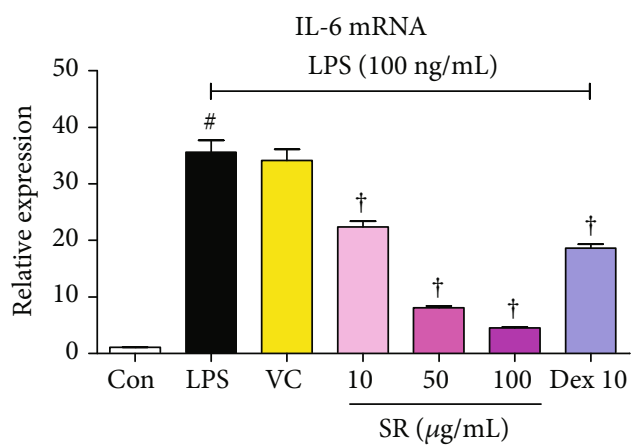

(f)

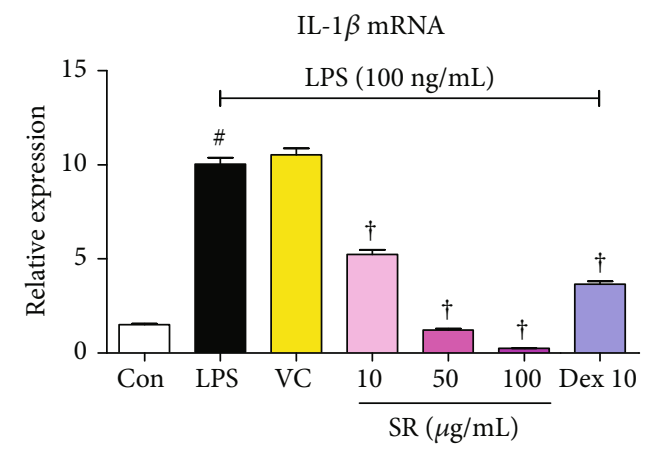

(g)

FIGURE 1: Effects of Saussureae Radix (SR) on (a) viability of microglia, secretion of (b) nitric oxide (NO) and (c, d) inflammatory cytokines, and (e-g) expression of cytokine mRNA in BV2 cells. Control cells were incubated with only fresh DMEM. BV2 cells were incubated with SR, vehicle control (VC; 0.1\% dimethyl sulfoxide (DMSO)), or stimulated with lipopolysaccharide (LPS) for 24 (a-d) or $12 \mathrm{~h}$ (e-g). TNF: tumor necrosis factor; IL: interleukin. ${ }^{*} p<0.05$ (vs. control); ${ }^{*} p<0.05$ and ${ }^{\dagger} p<0.001$ (vs. LPS). 
iNOS mRNA

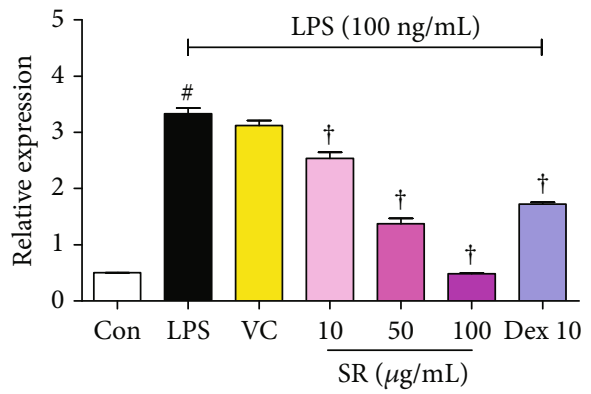

COX-2 mRNA

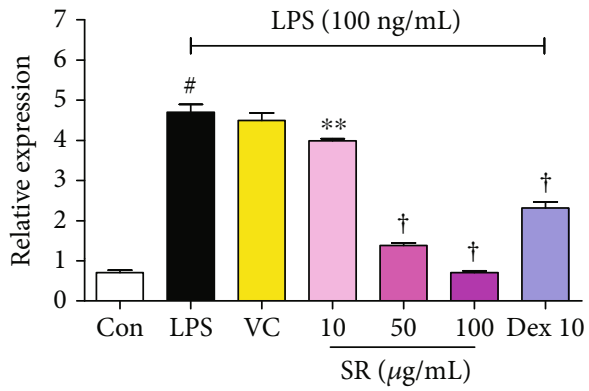

(a)

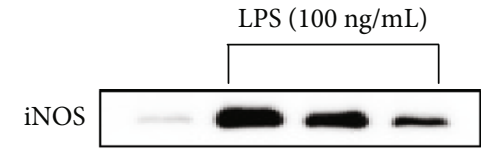

COX-2

$\beta$-Actin
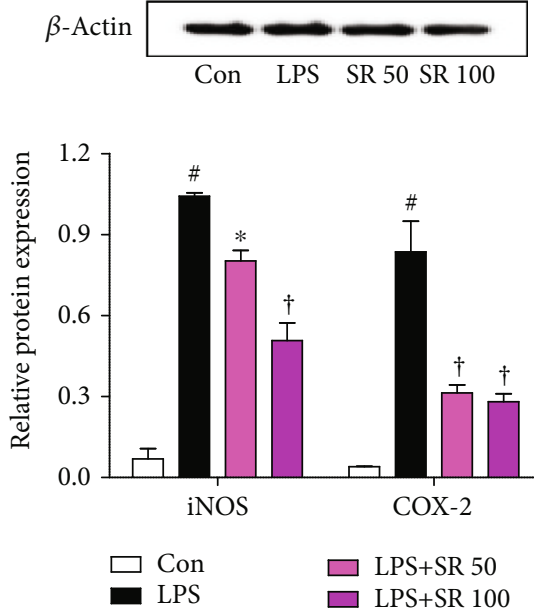

(b)
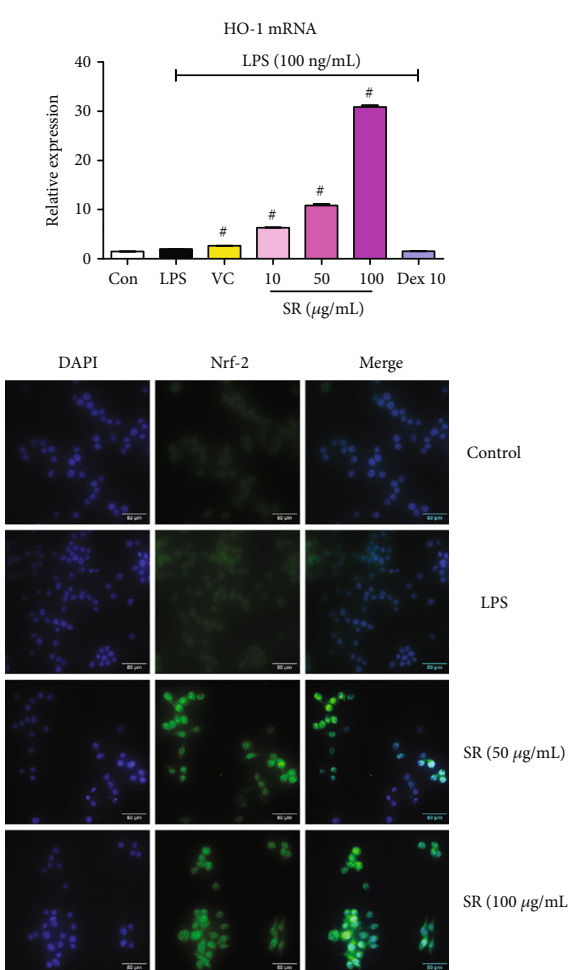

(c)
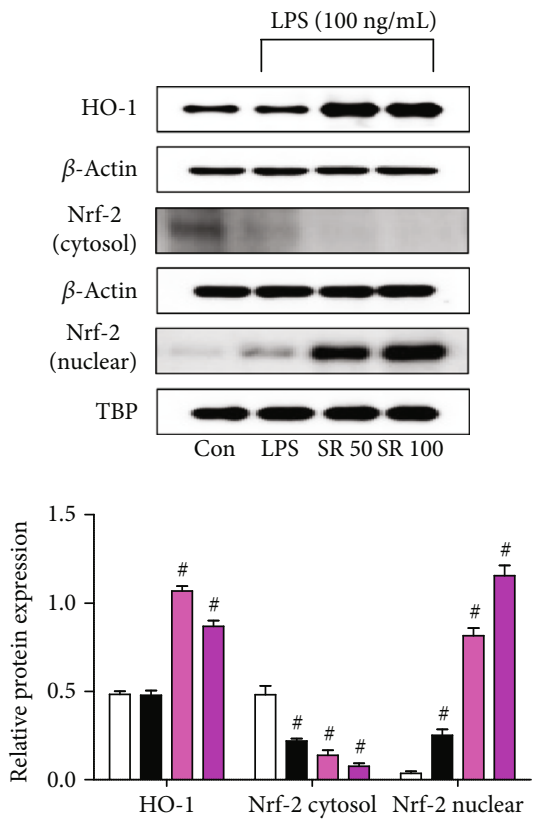

$\begin{array}{ll}\text { Con } & \square \text { LPS+SR } 50 \\ \text { LPS } & \square \text { LPS+SR } 100\end{array}$

(d)

FIGURE 2: Effects of Saussureae Radix (SR) on ( $\mathrm{a}, \mathrm{b})$ the expression of inducible nitric oxide synthase (iNOS) and cyclooxygenase- (COX-) 2, (c) the mRNA expression of heme oxygenase- (HO-) 1, and (d) the protein expression of HO-1 and nuclear translocation of nuclear factor erythroid 2-related factor 2 (Nrf-2). Control cells were incubated with only fresh DMEM. BV2 cells were stimulated with lipopolysaccharide (LPS) for 12 (iNOS and COX-2), 6 (HO-1 protein), or $3 \mathrm{~h}$ (HO-1 mRNA and Nrf-2). (b, d) The histogram graphs show protein expression levels relative to those of the housekeeping protein. (d) The cultured BV2 microglia were incubated with anti-Nrf-2 (green) and DAPI (blue). Fluorescence was developed using the Alexa Fluor 488 -conjugated anti-rabbit secondary antibody. ${ }^{*} p<0.05$ (vs. control); ${ }^{*} p<0.05$ and ${ }^{\dagger} p<0.001$ (vs. LPS).

(Figures 2(c) and 2(d)). The nuclear translocation of Nrf-2, which is the molecular mechanism that regulates $\mathrm{HO}-1$ induction, was also elevated by SR, and the extent of translocation was increased with increasing SR concentrations (Figure 2(d)). We also used immunofluorescence imaging to confirm the effect of SR on the nuclear translocation of Nrf-2 in BV2 cells and obtained results similar to those of Western blotting (Figure 2(d)).

3.5. Effects of $S R$ on the Transcriptional Activity of NF- $\kappa B$. Because the NF- $\kappa$ B pathway plays a pivotal role in the neu- roinflammatory process, we examined the inhibitory efficacy of SR on the phosphorylation of $\mathrm{I} \kappa \mathrm{B} \alpha$ and NF- $\kappa \mathrm{B}$ transactivation in LPS-stimulated microglia. Western blotting revealed that SR effectively inhibited p65 translocation from the cytoplasm to the nucleus in a concentration-dependent manner (Figure 3(a)). Additionally, SR strongly decreased the phosphorylation of $\mathrm{I} \kappa \mathrm{B} \alpha$ upon LPS stimulation (Figure 3(a)). Moreover, the nuclear translocation of p65 as identified using immunofluorescence imaging was strongly suppressed by SR pretreatment, in line with the Western blotting result (Figure 3(a)). 


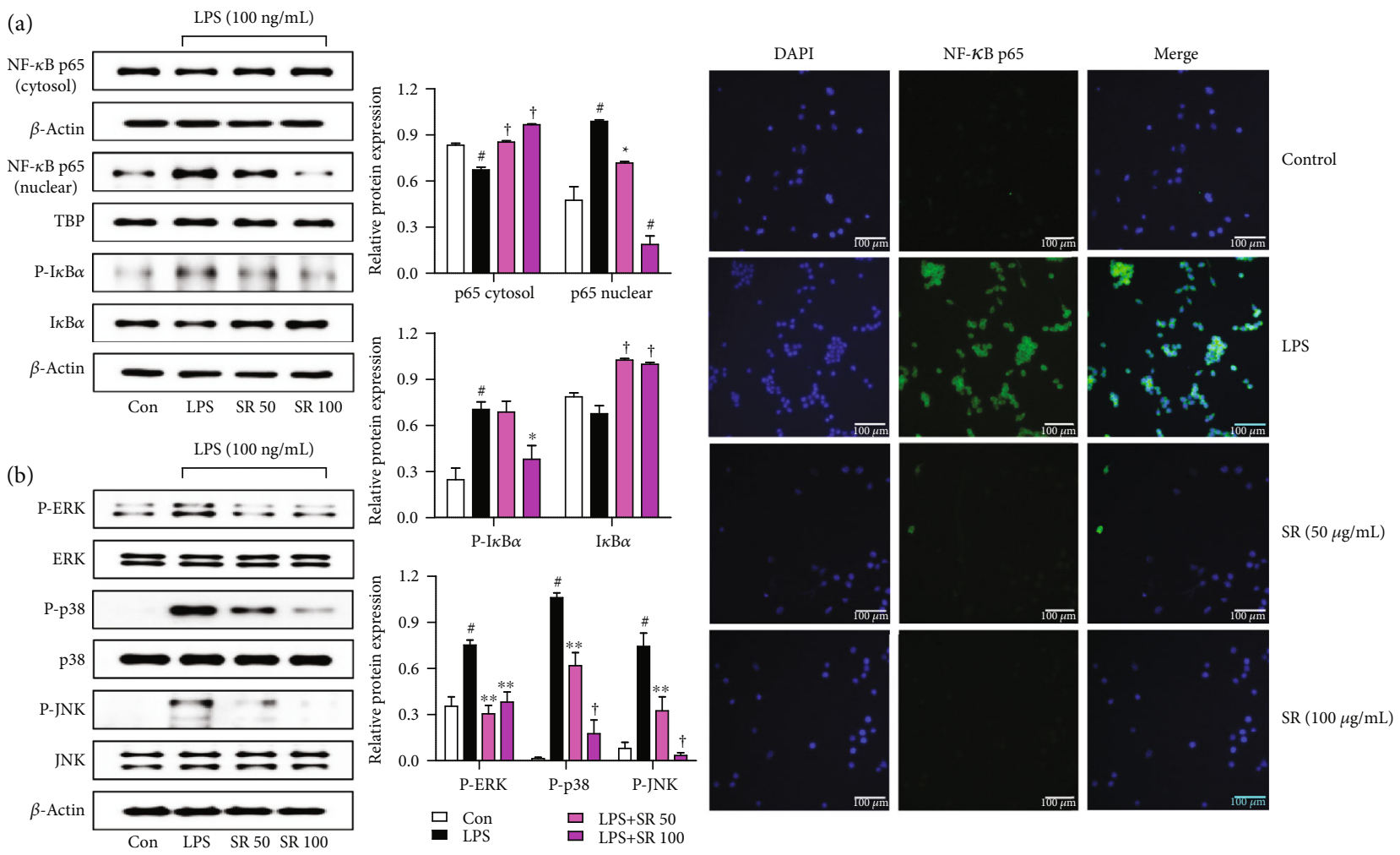

FIGURE 3: Effects of Saussureae Radix (SR) on the (a) nuclear translocation of nuclear factor- (NF-) $\kappa$ B p65 and phosphorylation of inhibitor of NF- $\kappa \mathrm{B}$ alpha $(\mathrm{I} \kappa \mathrm{B} \alpha)$ and $(\mathrm{b})$ phosphorylation of three mitogen-activated protein kinases (MAPKs). Control cells were incubated with only fresh DMEM. Cells were stimulated with lipopolysaccharide (LPS) for $1 \mathrm{~h}$ (NF- $\kappa \mathrm{B}$ p65) or $30 \mathrm{~min}$ (I $\kappa \mathrm{B} \alpha$ and MAPK). The histogram graphs show protein expression levels relative to those of the housekeeping protein. (a) The cultured BV2 microglia were incubated with anti-NF- $\kappa \mathrm{B}$ p65 (green) and DAPI (blue). Fluorescence was developed using the Alexa Fluor 488 -conjugated anti-rabbit secondary antibody. ${ }^{\#} p<0.05$ (vs. control); ${ }^{*} p<0.05,{ }^{* *} p<0.01$, and ${ }^{\dagger} p<0.001$ (vs. LPS).

3.6. Effects of SR on MAPK Phosphorylation. The phosphorylation of MAPK is involved in the production of many proinflammatory factors. Therefore, we analyzed the change of the phosphorylation of three MAPKs including extracellular signal-regulated kinase (ERK), p38, and c-Jun $\mathrm{NH}_{2}$-terminal kinase (JNK). Results of Figure 3(b) indicated that SR pretreatment repressed the activation of MAPKs, including ERK, p38, and JNK.

3.7. Effects of SR on LPS-Induced AP-1 Pathway Activation. AP-1 migrates to the nucleus and regulates the expression of certain inflammatory genes in response to inflammation caused by stimuli, such as LPS [6]. We therefore measured the level of AP-1 phosphorylation in the cytoplasm and nuclear AP-1 levels. As presented in Figure 4(a), LPS stimulation induced c-Jun phosphorylation and its migration to the nucleus, whereas pretreatment with SR inhibited the nuclear transfer and phosphorylation of c-Jun. The nuclear translocation of c-Fos, another subunit of AP-1, was also suppressed in a similar manner by SR pretreatment (Figure 4(a)).

3.8. Effects of SR on Activation of the JAK/STAT Pathway. Previous research reported that mitigation of the JAK/STAT pathway inhibited the secretion of $\mathrm{NO}$ and proinflammatory cytokines [18]. Therefore, we measured the inhibitory effects of SR on the phosphorylation of JAK2, STAT1, and STAT3 in LPS-stimulated BV2 cells. As presented in Figure 4(b), SR treatment significantly blocked the phosphorylation of JAK2, STAT1, and STAT3 without affecting their total protein levels.

3.9. Isolation and Structural Elucidation. Using combined chromatographic separation techniques, costunolide (1) and dehydrocostuslactone (2) were effectively isolated from SR (Figure 5). The HPLC evaluation showed that the purity of the isolated compounds was $>95 \%$. The structures were confirmed by comparing the obtained spectroscopic data with the previously reported values [19].

3.10. Verification of Antineuroinflammatory Effects of Costunolide and Dehydrocostuslactone in BV2 Microglia upon LPS Stimulation. To investigate the cytotoxicity of the main constituents of SR, we carried out CCK assays on microglia. As shown in Figure 6(a), costunolide showed no cytotoxicity at concentrations below $25 \mu \mathrm{M}$ and dehydrocostuslactone at concentrations below $10 \mu \mathrm{M}$. The two components showed slight cytotoxicity at concentrations greater than $25 \mu \mathrm{M}$ and $10 \mu \mathrm{M}$, respectively, so subsequent experiments used only concentrations below that. Also, both costunolide and dehydrocostuslactone effectively suppressed the production of NO and cytokines induced by LPS stimulation 

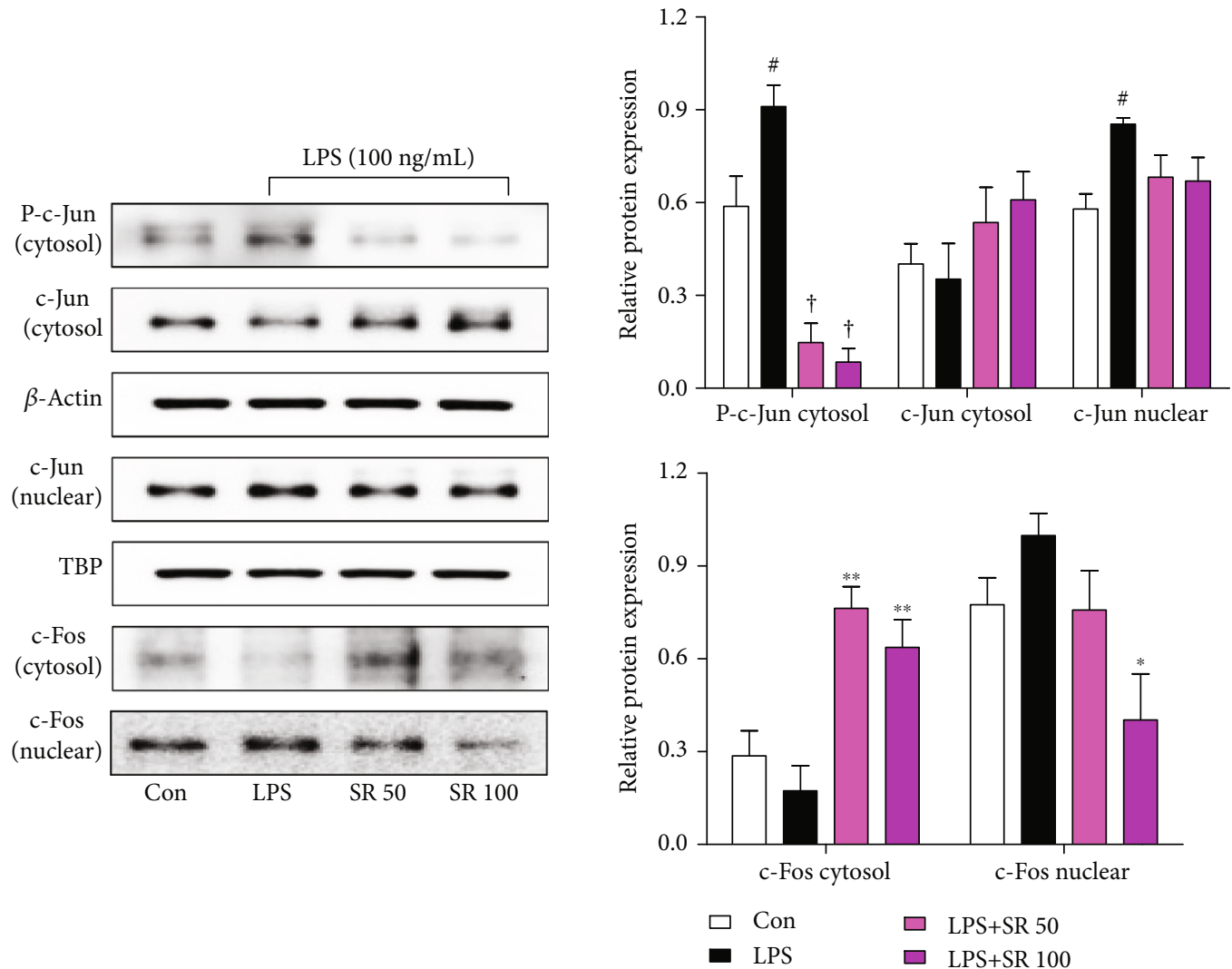

(a)
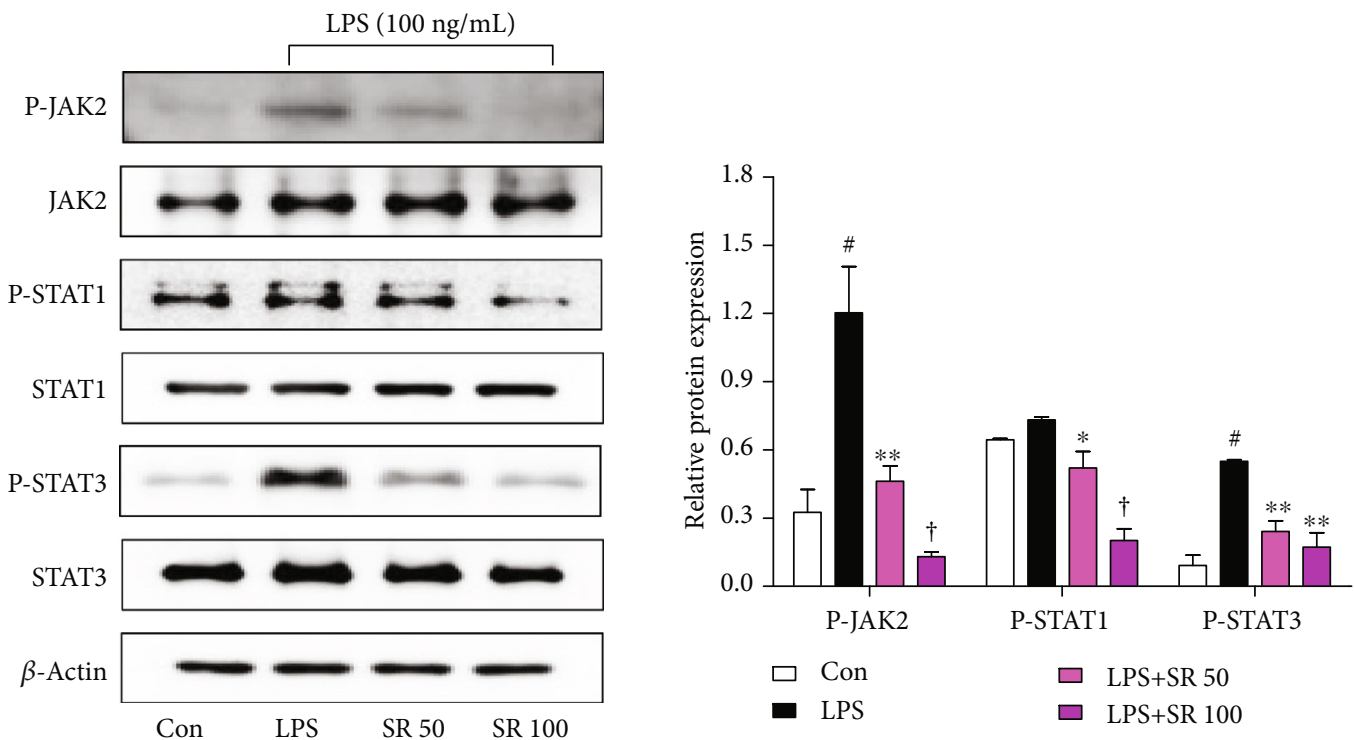

(b)

Figure 4: Effects of Saussureae Radix (SR) on the (a) nuclear translocation and phosphorylation of c-Jun and c-Fos and (b) phosphorylation of Janus kinase (JAK2), signal transducer and activator of transcription 1 (STAT1), and STAT3. Control cells were incubated with only fresh DMEM. Cells were stimulated with lipopolysaccharide (LPS) for (a) 1 or (b) $4 \mathrm{~h}$. The histograms show protein levels relative to those of the internal control. ${ }^{*} p<0.05$ (vs. control); ${ }^{*} p<0.05,{ }^{* *} p<0.01$, and ${ }^{\dagger} p<0.001$ (vs. LPS).

(Figures 6(b)-6(d)), and each mRNA expression was significantly and concentration-dependently suppressed (Figures 6(e)-6(g)). In addition, as shown in Figures 6(h)$6(\mathrm{j})$, the mRNA levels of iNOS and COX-2 were strongly suppressed by the pretreatment of costunolide and dehydrocos- tuslactone, and the expression of the antioxidant enzyme HO- 1 mRNA was effectively induced. The $0.1 \%$ DMSO used as a vehicle control had no effect on cell viability and the production of neuroinflammatory mediators. In most of the above results, costunolide and dehydrocostuslactone showed 


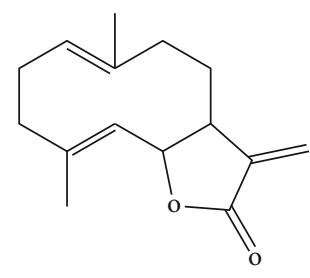

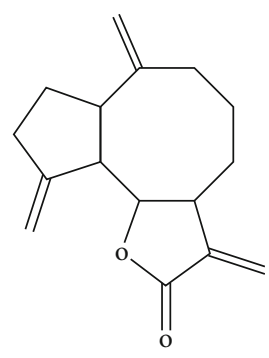

FIGURE 5: Structure of costunolide (1) and dehydrocostuslactone (2) isolated from SR.

concentration-dependent effects with statistical significance, respectively.

3.11. Identification of the Components of SR Using HPLC$D A D$ Analysis. The mobile phase consisted of methanol and water. Two standards and SR were detected using a PDA detector (200-400 nm). A wavelength of $200 \mathrm{~nm}$ was selected according to their maximum wavelength. By comparison of retention times (tR) and UV spectra of two standards (costunolide (1) (9.39 min) and dehydrocostuslactone (2) $(10.68 \mathrm{~min}))$ and SR, two compounds were detected (Figure 7).

3.12. Validation of the Analytical HPLC Method. The calibration curves for two compounds were obtained via plotting the peak area versus the concentration. The linear correlation coefficient $\left(R^{2}\right)$ for the calibration curves was greater than 0.999 (Table 3). According to the calibration curves, the amounts of two compounds were found to be $62.81996 \pm$ 0.0186 and $19.63455 \pm 0.0042 \mathrm{mg} / \mathrm{g}$, respectively.

\section{Discussion}

Microglial cell-mediated neuroinflammation has been identified as an important risk factor for neurodegenerative diseases. Overactivation of microglial cells leads to neuronal damage, brain injury, and the release of various neuroinflammatory mediators [20]. Reducing levels of these endogenous inflammatory factors through regulation of microglial activation is important in preventing and treating neuroinflammation [21]. SR is the dried root of Saussurea lappa Clarke (Compositae) and is native to the Himalayas in India. SR is listed in the ancient medicine text "Shennong's Classic of Materia Medica" and has long been used in East Asia to treat digestive disorders such as indigestion, vomiting, stomachache, diarrhea, and chronic inflammation of the digestive system. SR has also been used in the treatment of dysentery and testicular inflammation, and some recent studies have shown that SR can ameliorate reproductive toxicity in rats and alleviate house dust mite-induced atopic dermatitis in mice $[12,13]$. In addition, a recent review study described that SR exhibits anticancer, anti-inflammatory, antiulcer, and cholagogic effects [14]. Furthermore, another recent study shows that SR has antioxidant and antineuroinflammatory efficacy [22]. However, the above work used ethyl acetate fraction of SR and demonstrated inhibitory activity for NO, iNOS, and TNF- $\alpha$ cytokine production along with 2,2-diphenyl-1-picrylhydrazyl radical scavenging activity. Our present study demonstrated the inhibitory activity of SR on the generation of neuroinflammatory factors such as IL-6, IL-1 $\beta$, and COX-2 as well as NO in BV2 cells activated by LPS stimulation. We also revealed the molecular mechanisms of antineuroinflammatory activity through investigating the effects of SR on the NF- $\kappa$ B, MAPK, AP-1, and JAK/STAT pathways. Additionally, we have identified the efficacy of SR for activation of the HO-1/Nrf-2 antioxidant pathway.

First of all, we conducted a CCK assay to exclude the potential cytotoxicity of SR to BV2 microglial cells, and SR did not affect cell viability up to $100 \mu \mathrm{g} / \mathrm{mL}$. Furthermore, the proliferation of BV2 cells was confirmed when more than $50 \mu \mathrm{g} / \mathrm{mL}$ of SR was treated (Figure 1(a)). NO is a free radical that has been involved in the microglial cell-mediated inflammatory process in the CNS [23]. NO is synthesized from L-arginine by iNOS, and overproduction of $\mathrm{NO}$ is related to the presence of some inflammatory diseases and autoimmune disorders $[24,25]$. NO secretion and iNOS expression levels were closely related to $\mathrm{HO}-1$ induction [26], and HO-1 is regulated by Nrf-2. We therefore examined whether SR pretreatment inhibited the production of NO, inflammatory cytokines, iNOS, and COX-2 during the neuroinflammatory process upon LPS stimulation in microglial cells. Results of these experiments demonstrated that SR significantly reduced the production of NO, inflammatory cytokines, and its mRNAs without cytotoxicity (Figure 1) and inhibited the expression of iNOS and COX-2 protein and mRNA with statistical significance (Figures 2(a) and 2(b)). We further examined the effect of SR treatment on the induction of HO-1 and activation of Nrf-2. We found that SR markedly induced $\mathrm{HO}-1$ expression and gradually increased the nuclear translocation of Nrf-2 with statistical significance (Figures 2(c) and 2(d)). The efficacy of SR for HO-1 induction and Nrf-2 activation appears to have an indirect effect on regulating the neuroinflammatory response by inhibiting $\mathrm{NO}$ and iNOS.

The activation of NF- $\kappa \mathrm{B}$ and MAPK is associated with the pathogenesis in various diseases of CNS. NF- $\kappa$ B is the main regulator of various genes involved in immune and inflammatory reactions [27]. Depending on the activation of microglia by LPS, $\mathrm{I} \kappa \mathrm{B} \alpha$ is degraded and phosphorylated, in which free NF- $\kappa$ B is moved to the nucleus and activates inflammatory mediators [28]. MAPK plays an important role in the expression induced by LPS of some endogenous inflammatory mediators and the activation of NF- $\kappa \mathrm{B}[29$, 30]. We examined whether the influence of SR on inflammatory mediators is associated with the change of NF- $\kappa \mathrm{B}$. Our results showed that treatment of SR efficiently repressed the nuclear translocation of NF- $\kappa \mathrm{B}$ p65 in a concentrationdependent manner (Figure 3(a)). In addition, treatment of SR inhibited the phosphorylation and degradation of $\mathrm{I} \kappa \mathrm{B} \alpha$ in a similar pattern (Figure 3(a)). We also investigated the effects of SR on the phosphorylation of MAPK proteins following LPS stimulation, revealing that MAPK activation was effectively suppressed by SR treatment through inhibiting phosphorylation of ERK, p38, and JNK (Figure 3(b)). 
Cell viability

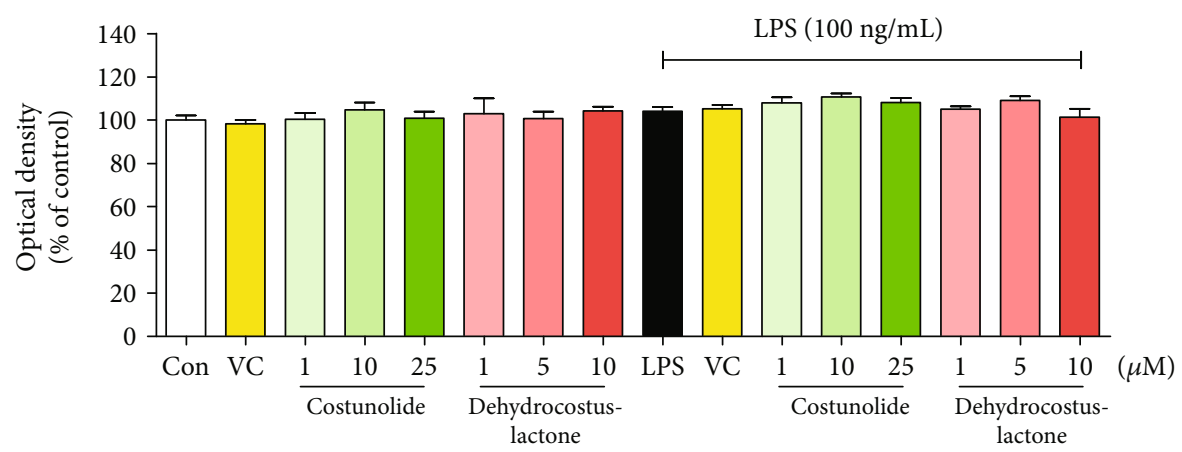

(a)

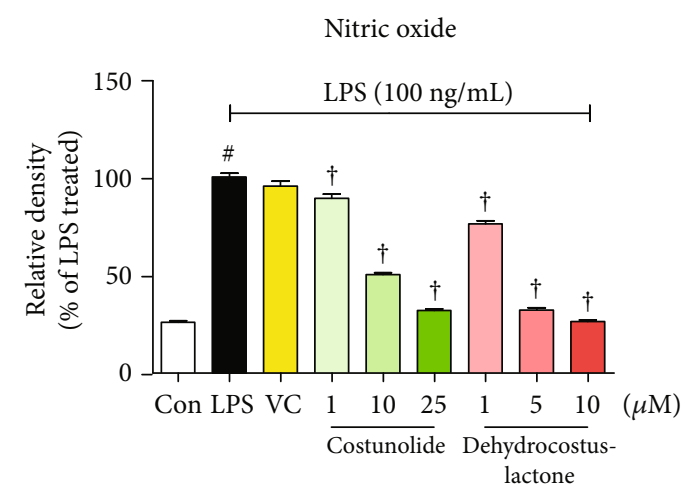

(b)

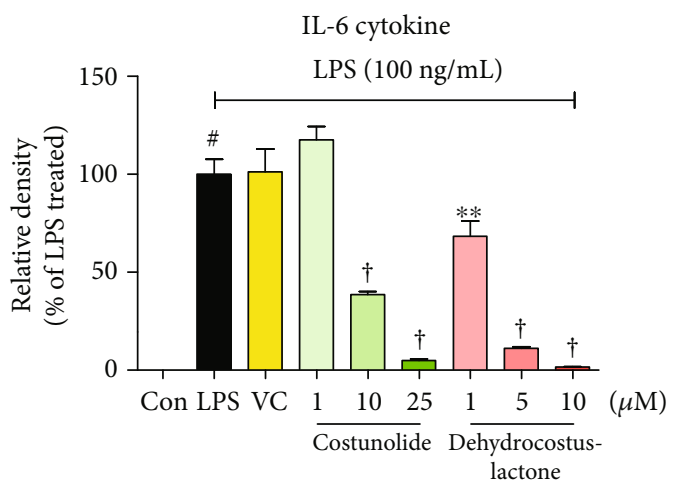

(d)

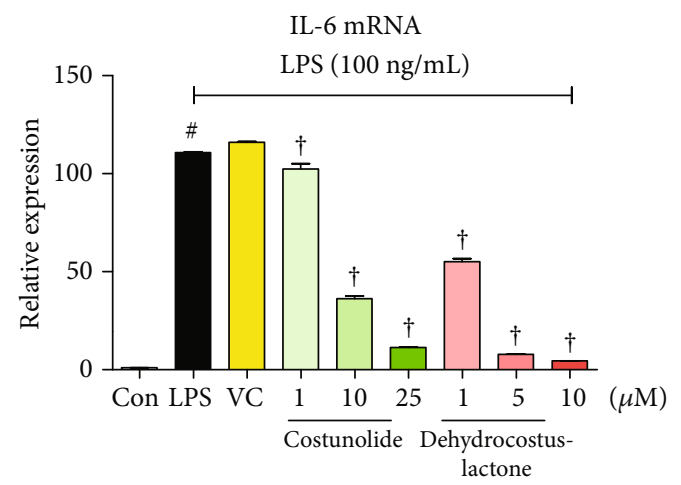

(f)

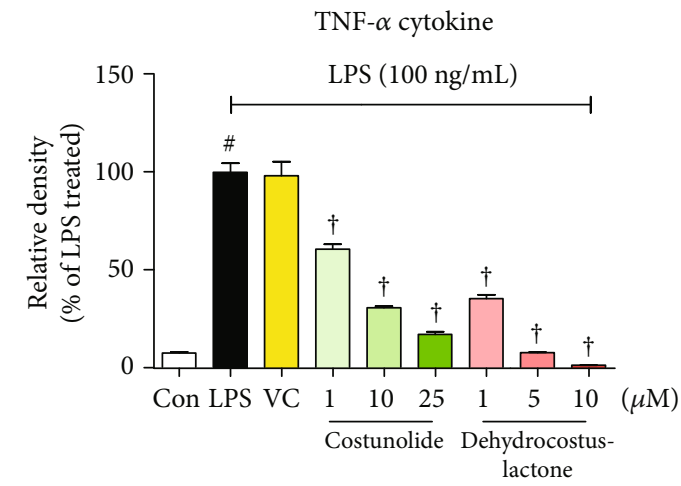

(c)

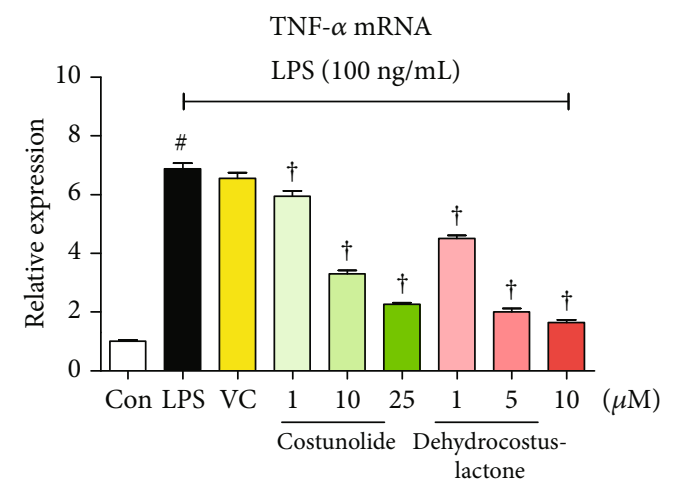

(e)

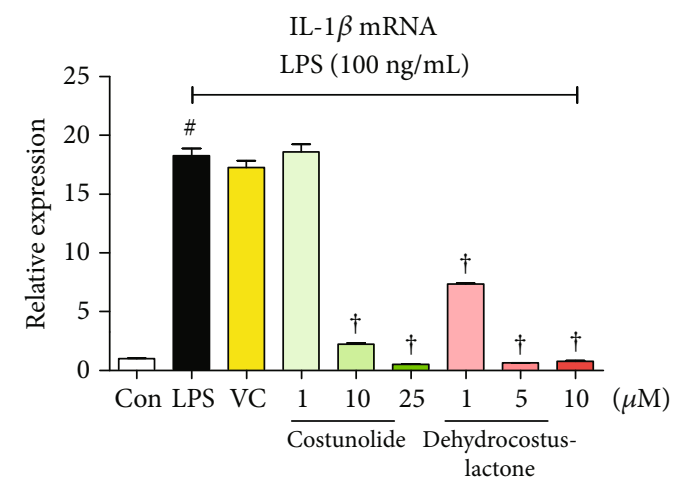

(g)

Figure 6: Continued. 


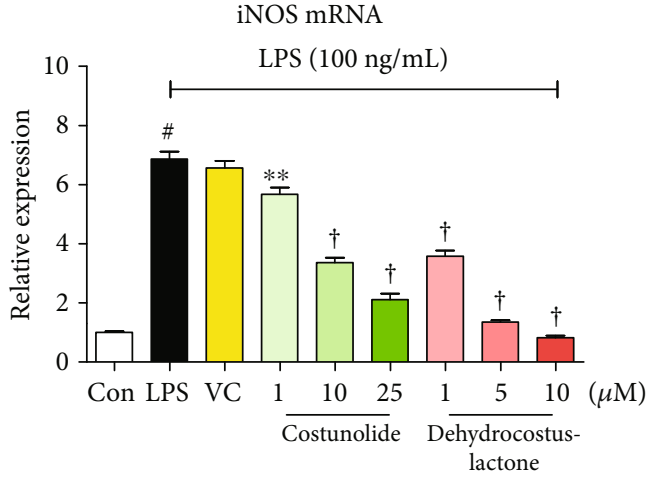

(h)

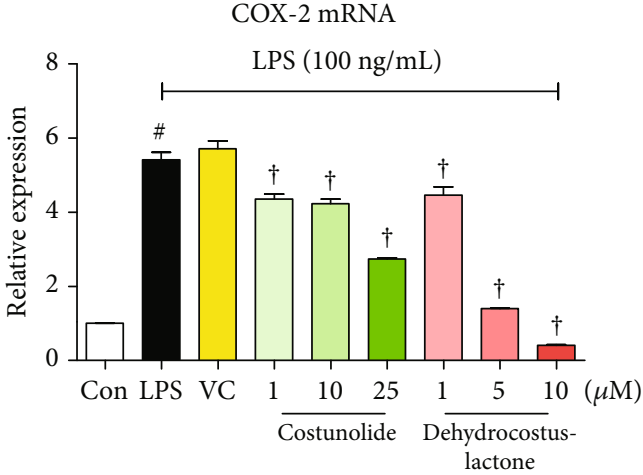

(i)

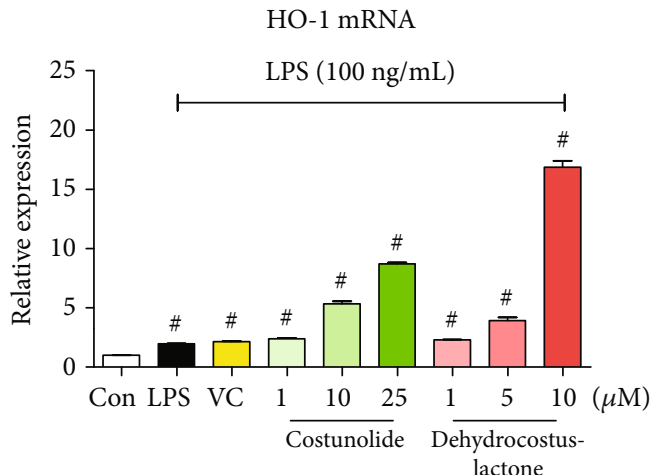

(j)

Figure 6: Effects of two compounds costunolide and dehydrocostuslactone on (a) viability of microglia, secretion of (b) nitric oxide (NO) and (c, d) inflammatory cytokines, and expression of (e-g) cytokine mRNAs, (h, i) inducible nitric oxide synthase (iNOS) and cyclooxygenase(COX-) 2 mRNAs, and (j) heme oxygenase- (HO-) 1 mRNA. Control cells were incubated with only fresh DMEM. BV2 cells were incubated with each compound, $0.1 \%$ dimethyl sulfoxide (DMSO), or stimulated with lipopolysaccharide (LPS) for 24 (a, b), 6 (c-g), 3 (h, i), or 6 h (j). ${ }^{*} p<0.05$ (vs. control); ${ }^{*} p<0.05,{ }^{* *} p<0.01$, and ${ }^{\dagger} p<0.001$ (vs. LPS).

These results indicated that the inhibitory effects of SR on neuroinflammation might be controlled via the blockade of the activation of NF- $\kappa \mathrm{B}$ and MAPK pathways.

The activation and nuclear translocation of AP-1 subunits regulate the expression of some inflammatory genes in inflammatory responses induced by LPS [6]. The JAK/STAT pathway is known to elicit the production of various inflammatory mediators through phosphorylation and is recognized to have a central role in inflammatory responses [6, 31]. In addition, the phosphorylation of STAT3 has a direct effect on IL-6 secretion [32]. We therefore examined the effects of SR on the phosphorylation of c-Jun and nuclear transfer of c-Jun and c-Fos following LPS treatment, and the results demonstrated that SR pretreatment inhibited both phosphorylation and nuclear translocation of c-Jun and suppressed translocation into the nucleus of c-Fos (Figure 4(a)). In addition, SR pretreatment effectively inhibited the phosphorylation of JAK2, STAT1, and STAT3 (Figure 4(b)). These results indicated that the antineuroinflammatory activity of SR was attributable to both the blockade of the $\mathrm{NF}-\kappa \mathrm{B}$ and MAPK pathways and the inhibition of the AP-1 and JAK/STAT pathways.

We also identified the two main components (costunolide and dehydrocostuslactone) of the SR using HPLC analysis. Previous studies of these components have shown that costunolide ameliorates acute lung injury via attenuating MAPK and improved acute ulcerative colitis in mice through inactivation of NF- $\kappa \mathrm{B}, \mathrm{STAT} 1 / 3$, and Akt $[33,34]$. There have also been reports that dehydrocostuslactone suppresses LPS-induced macrophage activation through NF- $\kappa \mathrm{B}, \mathrm{p} 38$ MAPK, and Akt [35]. Also, dehydrocostuslactone has been researched to be effective in inhibiting LPS-induced inflammation in vitro and improves the survival of mice in cecal ligation and puncture-induced sepsis in vivo [36]. These studies indicated that the antineuroinflammatory effect of SR is closely connected with the efficacy of its constituents, costunolide and dehydrocostuslactone. To confirm the antineuroinflammatory activity of these compounds, we investigated the effect of costunolide and dehydrocostuslactone on the production of $\mathrm{NO}$, proinflammatory cytokines, inflammatory mRNAs, and antioxidant enzyme $\mathrm{HO}-1$ on the microglia. Our results indicated that these compounds inhibited the production of $\mathrm{NO}$ and inflammatory cytokines including TNF- $\alpha$ and IL- 6 without cytotoxicity at each concentration (Figures 6(a)-6(d)). Also, two compounds suppressed the expression of cytokine, iNOS, and COX-2 mRNA in a concentration-dependent manner (Figures 6(e)-6(i)). In addition, costunolide and dehydrocostuslactone strongly induced HO-1 mRNA expression (Figure $6(j)$ ). Based on the above results, the regulatory 


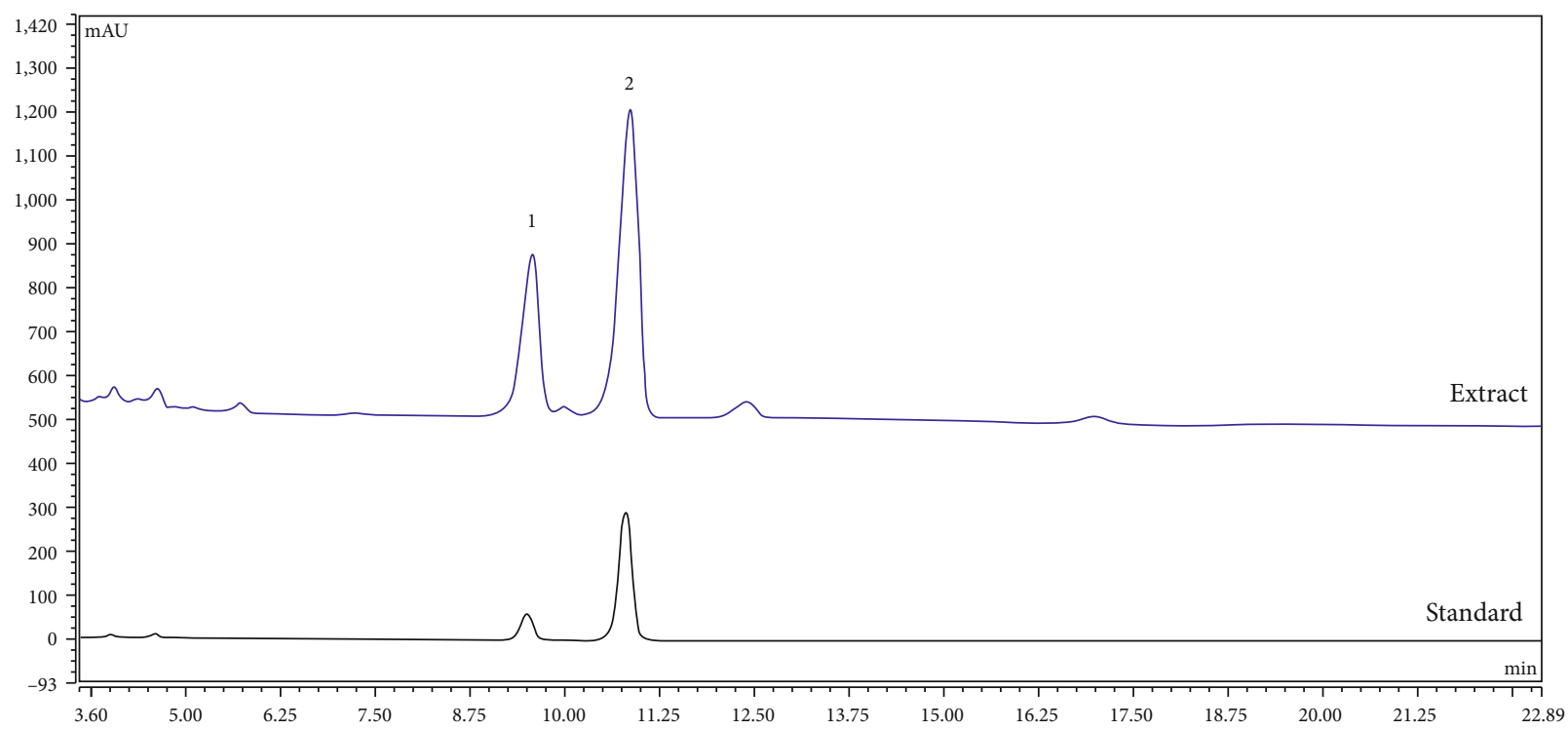

(a)

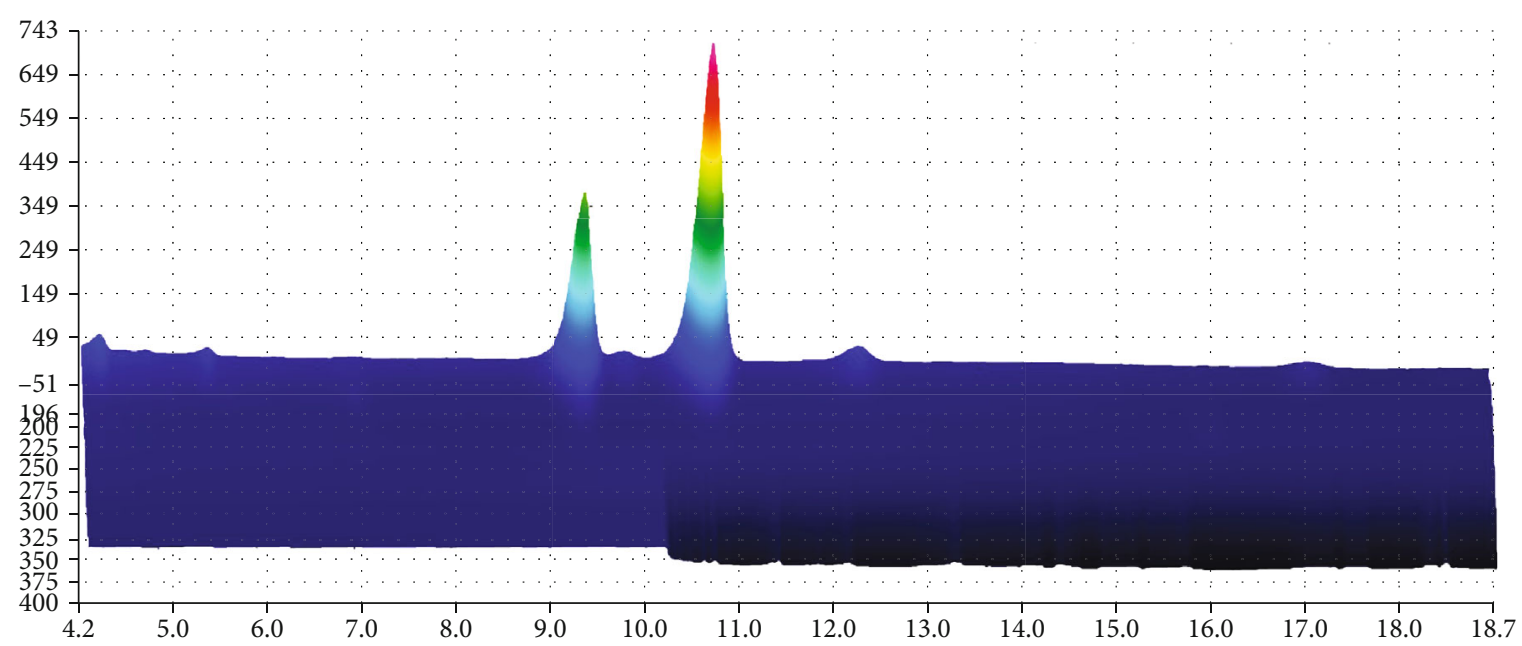

(b)

Figure 7: Continued. 

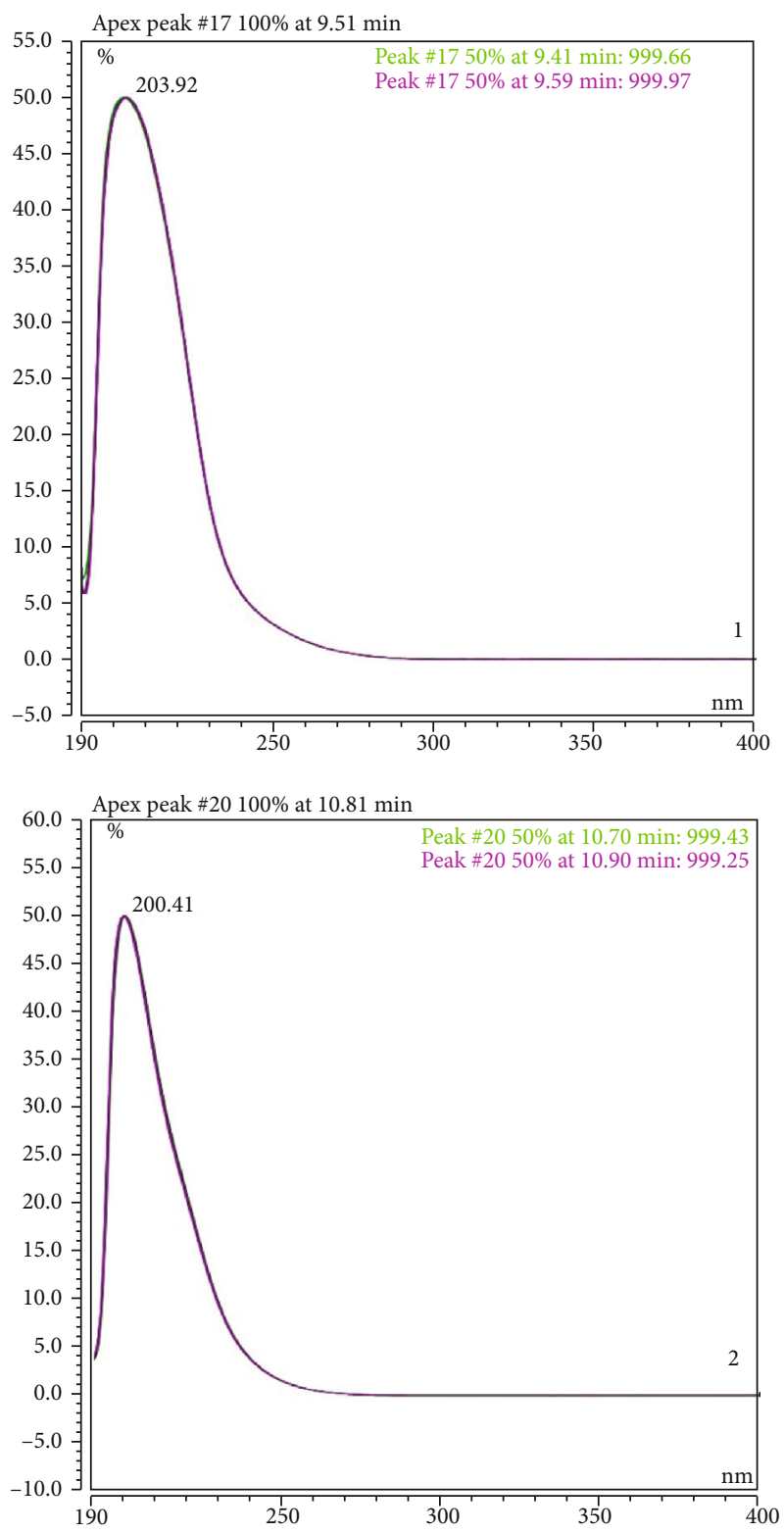

(c)

FiguRE 7: HPLC chromatograms ((a) 2D; (b) 3D) of two standard compounds from the ethanolic extract of SR at UV wavelengths of $200 \mathrm{~nm}$ (c). Costunolide (1) (9.39 min) and dehydrocostuslactone (2) (10.68 min) were identified.

TABLE 3: Regression data and contents of two compounds in SR.

\begin{tabular}{lccc}
\hline Analytes & Regression equation & $R^{2}$ & Content (mg/g) \\
\hline Costunolide (1) & $y=0.173 x+0.0257$ & 0.9999 & $62.81996 \pm 0.0186$ \\
Dehydrocostuslactone (2) & $y=1.0619 x+9.5492$ & 0.9994 & $19.63455 \pm 0.0042$ \\
\hline
\end{tabular}


efficacy of SR on the neuroinflammatory response is thought to be closely related to the inhibitory efficacy of costunolide and dehydrocostuslactone on the production of inflammatory mediators.

The results of this study showed that SR contains antineuroinflammatory properties in vitro by attenuating inhibiting inflammatory mediators in LPS-stimulated BV2 cells. These beneficial activities are associated with enhanced HO- $1 /$ Nrf- 2 activation and inhibition of the NF- $\kappa$ B/MAPK/AP-1/JAK/STAT signaling pathways. The antineuroinflammatory effects of SR appear to be closely related to the presence of two components, costunolide and dehydrocostuslactone. Based on these results, SR appears to have potential value as a candidate for the treatment of inflammationrelated degenerative brain diseases.

\section{Abbreviations}

$\begin{array}{ll}\text { AP: } & \text { Activator protein } \\ \text { BSA: } & \text { Bovine serum albumin } \\ \text { CCK: } & \text { Cell-counting kit } \\ \text { CNS: } & \text { Central nervous system } \\ \text { CO: } & \text { Carbon monoxide } \\ \text { COX: } & \text { Cyclooxygenase } \\ \text { DAD: } & \text { Diode array UV/VIS detector } \\ \text { DAPI: } & \text { 4,6-Diamidino-2-phenylindole } \\ \text { DMEM: } & \text { Dulbecco's modified Eagle's medium } \\ \text { DMSO: } & \text { Dimethyl sulfoxide } \\ \text { ELISA: } & \text { Enzyme-linked immunosorbent assay } \\ \text { ERK: } & \text { Extracellular signal-regulated kinase } \\ \text { FBS: } & \text { Fetal bovine serum } \\ \text { HO: } & \text { Heme oxygenase } \\ \text { HPLC: } & \text { High-performance liquid chromatography } \\ \text { HRP: } & \text { Horseradish peroxidase } \\ \text { IL: } & \text { Interleukin } \\ \text { iNOS: } & \text { Inducible nitric oxide synthase } \\ \text { JAK: } & \text { Janus kinase } \\ \text { JNK: } & \text { c-Jun NH } \text {-terminal kinase } \\ \text { LPS: } & \text { Lipopolysaccharide } \\ \text { MAPK: } & \text { Mitogen-activated protein kinase } \\ \text { NF: } & \text { Nuclear factor } \\ \text { NO: } & \text { Nitric oxide } \\ \text { Nrf-2: } & \text { Nuclear factor erythroid 2-related factor } 2 \\ \text { PBS: } & \text { Phosphate-buffered saline } \\ \text { RT-qPCR: } & \text { Real-time reverse transcription-polymerase } \\ & \text { chain reaction } \\ \text { SR: } & \text { Saussureae Radix } \\ \text { STAT: } & \text { Signal transducer and activator of transcription } \\ \text { TNF: } & \text { Tumor necrosis factor } \\ \text { VC: } & \text { Vehicle control. } \\ & \end{array}$

\section{Data Availability}

The data used to support the findings are available from the corresponding author upon request.

\section{Conflicts of Interest}

The authors declare that there are no conflicts of interest.

\section{Authors' Contributions}

You-Chang Oh developed the study design, performed the experiments, analyzed the data, wrote the draft manuscript, and critically revised the manuscript. Wei Li performed the experiments, analyzed the data, and performed the phytochemical analysis. Jang-Gi Choi performed the experiments and analyzed the data. All authors contributed to the article and approved the submitted version.

\section{Acknowledgments}

This research was supported by Grant KSN2013230 from the Korea Institute of Oriental Medicine (KIOM), provided by the Ministry of Science and ICT, Republic of Korea.

\section{References}

[1] J. Gehrmann, Y. Matsumoto, and G. W. Kreutzberg, "Microglia: intrinsic immuneffector cell of the brain," Brain Research Reviews, vol. 20, no. 3, pp. 269-287, 1995.

[2] I. Glezer, A. R. Simard, and S. Rivest, "Neuroprotective role of the innate immune system by microglia," Neuroscience, vol. 147, no. 4, pp. 867-883, 2007.

[3] V. Y. Kosovrasti, L. V. Nechev, and M. M. Amiji, "Peritoneal macrophage-specific TNF- $\alpha$ gene silencing in LPS-induced acute inflammation model using CD44 targeting hyaluronic acid nanoparticles," Molecular Pharmaceutics, vol. 13, no. 10, pp. 3404-3416, 2016.

[4] J. Chun, R. J. Choi, S. Khan et al., "Alantolactone suppresses inducible nitric oxide synthase and cyclooxygenase-2 expression by down-regulating NF- $\kappa \mathrm{B}$, MAPK and AP-1 via the MyD88 signaling pathway in LPS-activated RAW 264.7 cells," International Immunopharmacology, vol. 14, no. 4, pp. 375383, 2012.

[5] R. Wisdom, "AP-1: one switch for many signals," Experimental Cell Research, vol. 253, no. 1, pp. 180-185, 1999.

[6] P. J. Murray, "The JAK-STAT signaling pathway: input and output integration," Journal of Immunology, vol. 178, no. 5, pp. 2623-2629, 2007.

[7] R. Tenhunen, H. S. Marver, and R. Schmid, "The enzymatic catabolism of hemoglobin: stimulation of microsomal heme oxygenase by hemin," Journal of Laboratory and Clinical Medicine, vol. 75, no. 3, pp. 410-421, 1970.

[8] L. E. Otterbein, F. H. Bach, J. Alam et al., "Carbon monoxide has anti-inflammatory effects involving the mitogen- activated protein kinase pathway," Nature Medicine, vol. 6, no. 4, pp. 422-428, 2000.

[9] G. S. Oh, H. O. Pae, B. S. Lee et al., "Hydrogen sulfide inhibits nitric oxide production and nuclear factor- $\kappa \mathrm{B}$ via heme oxygenase-1 expression in RAW264.7 macrophages stimulated with lipopolysaccharide," Free Radical Biology and Medicine, vol. 41, no. 1, pp. 106-119, 2006.

[10] C. S. Lim, D. Q. Jin, H. Mok et al., "Antioxidant and antiinflammatory activities of xanthorrhizol in hippocampal neurons and primary cultured microglia," Journal of Neuroscience Research, vol. 82, no. 6, pp. 831-838, 2005.

[11] H. Kumar, S. Koppula, I. S. Kim, S. V. More, B. W. Kim, and D. K. Choi, "Nuclear factor erythroid 2-related factor 2 signaling in Parkinson disease: a promising multi therapeutic target against oxidative stress, neuroinflammation and cell death," 
CNS and Neurological Disorders Drug Targets, vol. 11, no. 8, pp. 1015-1029, 2012.

[12] M. A. Abd Eldaim, E. Tousson, I. E. T. el Sayed, and W. M. Awd, "Ameliorative effects of Saussurea lappa root aqueous extract against ethephon-induced reproductive toxicity in male rats," Environmental Toxicology, vol. 34, no. 2, pp. 150$159,2019$.

[13] H. S. Lim, H. Ha, M. Y. Lee et al., "Saussurea lappa_alleviates inflammatory chemokine production in $\mathrm{HaCaT}$ cells and house dust mite-induced atopic-like dermatitis in $\mathrm{Nc} / \mathrm{Nga}$ mice," Food and Chemical Toxicology, vol. 63, pp. 212-220, 2014.

[14] K. Zahara, S. Tabassum, S. Sabir et al., "A review of therapeutic potential of Saussurea lappa-An endangered plant from Himalaya," Asian Pacific Journal of Tropical Medicine, vol. 7, no. S1, pp. S60-S69, 2014.

[15] Y. C. Oh, Y. H. Jeong, W. Li, and Y. Go, “Angelicae Gigantis Radix regulates LPS-induced neuroinflammation in BV2 microglia by inhibiting NF- $\kappa$ B and MAPK activity and inducing Nrf-2 activity," Molecules, vol. 24, no. 20, p. 3755, 2019.

[16] M. M. Bradford, "A rapid and sensitive method for the quantitation of microgram quantities of protein utilizing the principle of protein-dye binding," Analytical Biochemistry, vol. 72, no. 1-2, pp. 248-254, 1976.

[17] J. G. Choi, H. Lee, Y. S. Kim et al., “Aloe veraand its components inhibit influenza A virus-induced autophagy and replication," American Journal of Chinese Medicine, vol. 47, no. 6, pp. 1307-1324, 2019.

[18] L. Samavati, R. Rastogi, W. du, M. Hüttemann, A. Fite, and L. Franchi, "STAT3 tyrosine phosphorylation is critical for interleukin 1 beta and interleukin-6 production in response to lipopolysaccharide and live bacteria," Molecular Immunology, vol. 46, no. 8-9, pp. 1867-1877, 2009.

[19] B. Ferrari, P. Castilho, F. Tomi, A. I. Rodrigues, M. do Ceu Costa, and J. Casanova, "Direct identification and quantitative determination of costunolide and dehydrocostuslactone in the fixed oil of Laurus novocanariensis by 13C-NMR spectroscopy," Phytochemical Analysis, vol. 16, no. 2, pp. 104-107, 2005.

[20] L. E. Rojo, J. A. Fernández, A. A. Maccioni, J. M. Jimenez, and R. B. Maccioni, "Neuroinflammation: implications for the pathogenesis and molecular diagnosis of Alzheimer's disease," Archives of Medical Research, vol. 39, no. 1, pp. 1-16, 2008.

[21] C. K. Glass, K. Saijo, B. Winner, M. C. Marchetto, and F. H. Gage, "Mechanisms underlying inflammation in neurodegeneration," Cell, vol. 140, no. 6, pp. 918-934, 2010.

[22] S. G. Lee and H. Kang, "Saussurea lappa Clarke extract exhibits potent antioxidant effect and attenuates neuroinflammatory responses in lipopolysaccharide-stimulated microglial cells," Tropical Journal of Pharmaceutical Research, vol. 19, no. 9, pp. 1911-1917, 2020.

[23] P. Tripathi, P. Tripathi, L. Kashyap, and V. Singh, "The role of nitric oxide in inflammatory reactions," FEMS Immunology and Medical Microbiology, vol. 51, no. 3, pp. 443-452, 2007.

[24] T. J. Guzik, R. Korbut, and T. Adamek-Guzik, "Nitric oxide and superoxide in inflammation and immune regulation," Journal of Physiology and Pharmacology, vol. 54, no. 4, pp. 469-487, 2003.

[25] G. J. Southan and C. Szabo, "Selective pharmacological inhibition of distinct nitric oxide synthase isoforms," Biochemical Pharmacology, vol. 51, no. 4, pp. 383-394, 1996.
[26] T. Ashino, R. Yamanaka, M. Yamamoto et al., "Negative feedback regulation of lipopolysaccharide-induced inducible nitric oxide synthase gene expression by heme oxygenase- 1 induction in macrophages," Molecular Immunology, vol. 45, no. 7, pp. 2106-2115, 2008.

[27] N. R. Chapman and N. D. Perkins, "Inhibition of the RelA(p65) NF- $\kappa$ B subunit by Egr-1*," Journal of Biological Chemistry, vol. 275, no. 7, pp. 4719-4725, 2000.

[28] J. Brown, H. Wang, G. N. Hajishengallis, and M. Martin, "TLR-signaling networks," Journal of Dental Research, vol. 90, no. 4, pp. 417-427, 2011.

[29] B. W. Kim, S. Koppula, S. S. Hong et al., "Regulation of microglia activity by glaucocalyxin-A: attenuation of lipopolysaccharide-stimulated neuroinflammation through NF- $\kappa \mathrm{B}$ and p38 MAPK signaling pathways," PLoS One, vol. 8, no. 2, article e55792, 2013.

[30] A. R. Kim, M. S. Lee, J. W. Choi et al., "Phlorofucofuroeckol A suppresses expression of inducible nitric oxide synthase, cyclooxygenase-2, and pro-inflammatory cytokines via inhibition of nuclear factor- $\kappa \mathrm{B}$, c-Jun NH2-terminal kinases, and Akt in microglial cells," Inflammation, vol. 36, no. 2, pp. 259-271, 2013.

[31] D. Guo, J. R. Li, Y. Wang, L. S. Lei, C. L. Yu, and N. N. Chen, "Cyclovirobuxinum D suppresses lipopolysaccharide-induced inflammatory responses in murine macrophages _in vitro_ by blocking JAK-STAT signaling pathway," Acta Pharmacologica Sinica, vol. 35, no. 6, pp. 770-778, 2014.

[32] B. G. Jung, X. Wang, N. Yi, J. Ma, J. Turner, and B. Samten, "Early Secreted Antigenic Target of 6-kDa of Mycobacterium tuberculosis Stimulates IL-6 Production by Macrophages through Activation of STAT3," Scientific Reports, vol. 7, no. 1, p. 40984, 2017.

[33] Z. Chen, D. Zhang, M. Li, and B. Wang, "Costunolide ameliorates lipoteichoic acid-induced acute lung injury via attenuating MAPK signaling pathway," International Immunopharmacology, vol. 61, pp. 283-289, 2018.

[34] F. Xie, H. Zhang, C. Zheng, and X. F. Shen, "Costunolide improved dextran sulfate sodium-induced acute ulcerative colitis in mice through NF- $\kappa \mathrm{B}, \mathrm{STAT} 1 / 3$, and Akt signaling pathways," International Immunopharmacology, vol. 84, p. 106567, 2020.

[35] Y. Nie, Z. Wang, G. Chai et al., "Dehydrocostus lactone suppresses LPS-induced acute lung injury and macrophage activation through $\mathrm{NF}-\kappa \mathrm{B}$ signaling pathway mediated by $\mathrm{p} 38$ MAPK and Akt," Molecules, vol. 24, no. 8, p. 1510, 2019.

[36] E. J. Park, S. W. Park, H. J. Kim, J. H. Kwak, D. U. Lee, and K. C. Chang, "Dehydrocostuslactone inhibits LPS-induced inflammation by p38MAPK-dependent induction of hemeoxygenase-1 in vitro and improves survival of mice in CLP- induced sepsis in vivo," International Immunopharmacology, vol. 22, no. 2, pp. 332-340, 2014. 